\title{
Monitoring of the ultrasonic $P$-wave velocity in early-age concrete using Smart Aggregates
}

\author{
Cédric Dumoulin, Grigoris Karaiskos, Jérôme Carette, Stéphanie Staquet, and Arnaud Deraemaeker a \\ Université Libre de Bruxelles - BATir \\ 50 av F.D. Roosevelt, CP 194/02 \\ B-1050 Brussels, Belgium
}

\begin{abstract}
This paper deals with the use of embedded piezoelectric transducers to monitor the ultrasonic $P$ wave velocity evolution during the setting and hardening phases of concrete since casting time. The main advantage of the technique is the ability to overcome the limitations of traditional methods which do not allow to apply specific mechanical boundary conditions during the measurement. The embedded transducers are based on the "Smart Aggregates" concept previously developed at the University of Houston, Texas. Two piezoelectric transducers are embedded in a prismatic mold and the evolution of the $P$-wave velocity is recorded for the first 24 hours in concrete after casting time. The results are very promising and show a good agreement with classical ultrasonic tests using external transducers.
\end{abstract}

\section{Introduction}

In most concrete applications, setting and hardening of concrete are important parameters to assess the period during which concrete is still workable and the time when the formwork can be removed. In addition, such information is also useful for a better understanding of the development of the microstructure and the effect of admixtures and mineral additions on the hydration of the cement. Conventional methods to measure these parameters are the Vicat needle test (EN 196-3) for cement paste and the penetration resistance test (ASTM C403) for mortar. The main drawback of these methods is that they do not allow to perform the test twice at the same location due to their destructive nature, and the fact that they are not applicable to concrete (due to the presence of aggregates). More recently, NDT (non destructive testing) ultrasonic devices, previously developed for damage detection and crack identification, have been used to monitor the transition from fluid to solid and the change in stiffness of early age concrete. One example is the Freshcon system developed at the University of Stuttgart $[1,2]$ which is represented on Figure 1. It consists in a specific mold (for concrete or mortar) equipped with two piezoeletric transducers (one transmitter and one receiver). A computer equipped with a data acquisition card is linked to a piezoelectric high voltage pulser to generate a high voltage short rectangular wave (typically $800 \mathrm{~V}$ with a pulse width of $2.5 \mu \mathrm{s}$ ). A wide band ultrasonic (mechanical) wave is generated and picked up by the receiver of which the signal is amplified after traveling through the material. The software in the computer automatically computes the time it takes for the wave to travel from the transmitter to the receiver and deduces the velocity of the wave. The system is able to compute the velocity of both compressive $(P)$ and shear $(S)$ waves using dedicated molds and transducers. The study presented in this paper is however restricted to $P$-waves. The velocity of $S$ and $P$ waves

\footnotetext{
a e-mail: aderaema@ulb.ac.be
}

can be used to computed the dynamic Young's modulus and Poisson's ratio.

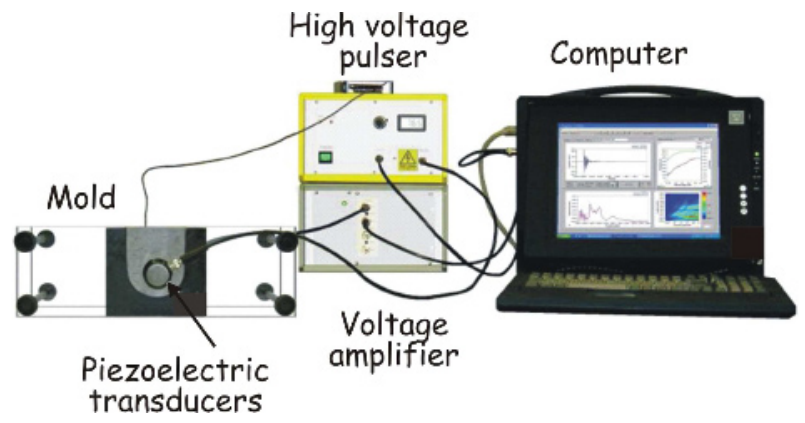

Fig. 1. The Freshcon System [1]

At ULB-BATir, we have been working successfully with the Freshcon system for several years to study the early age properties of different concrete mixtures [3]. There are however limitations to the system mainly linked to the fixed design of the mold which only allows to vary the temperature during the tests and does not allow to apply specific hygral and/or mechanical boundary conditions on the concrete sample (such as free or restrained shrinkage). The main idea presented in this paper is to study the possibility to embed the piezoelectric transducers directly inside concrete specimen of different sizes and geometries designed for specific mechanical tests. In particular, we are interested in embedding such transducers in a TSTM machine (temperature-stress testing machine) for a better understanding of the early age behavior of concrete in traction. 


\section{Embedded piezoelectric transducers}

Flat piezoelectric transducers are widely used in applications such as active vibration control, shape control and structural health monitoring. While they are used primarily for applications involving thin metallic or composite structures, they can also be used in concrete where they are either surface mounted or embedded. A successful implementation of embedded transducers called "Smart Aggregates" (SMAG) has been recently developed at the University of Houston $[4,5]$ and used mainly to monitor the compressive strength and crack evolution in concrete structures. The SMAGs consists in a flat piezoelectric PZT patch (of approximate size $12 \mathrm{~mm} \times 12 \mathrm{~mm} \times 0.2 \mathrm{~mm}$ ) which is wrapped in a waterproof coating and embedded in a small cube or cylinder made of mortar (Figure 2). The SMAGs used in this study have been designed and fabricated in our department at ULB-BATir.

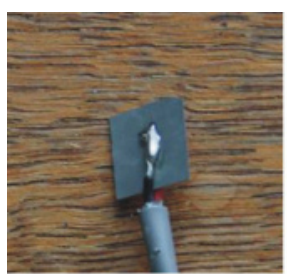

a) Piezoelectric patch

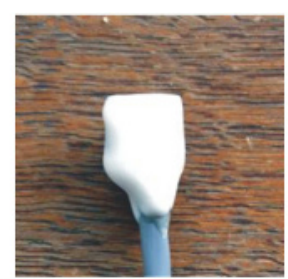

b) with waterproof coating

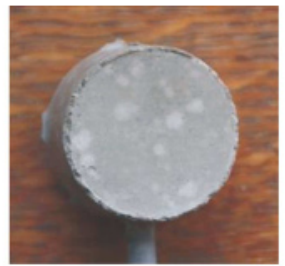

c) Smart Aggregate

Fig. 2. Principle of a Smart Aggregate (SMAG) : a) Piezoelectric patch, b) Patch with waterproof coating, c) Smart Aggregate [4]

\section{Experimental test}

In order to test the feasibility of using SMAGs to measure the $P$-wave velocity of early-age concrete, two prismatic molds, each containing a pair of SMAGS have been prepared. Two distances between the SMAGs have been tested: $d=6 \mathrm{~cm}$ and $d=10 \mathrm{~cm}$ (Figure 3). The tests are made on an ordinary concrete (cement $\left(340 \mathrm{~kg} / \mathrm{m}^{3}\right)$ : CEMI $52.5 \mathrm{~N}$, sand $\left(739 \mathrm{~kg} / \mathrm{m}^{3}\right)$ : Bernières $0 / 4$, gravel $\left(1072 \mathrm{~kg} / \mathrm{m}^{3}\right)$ : Bernières $8 / 22$, water $\left.\left(184 \mathrm{~kg} / \mathrm{m}^{3}\right)\right)$.

In a first step, a calibration test was performed by filling the two molds with water, knowing that the velocity of $P$-waves in water is $1498 \mathrm{~m} / \mathrm{s}$ and measuring accurately the distance between the transducers. The Freshcon system was used to generated the pulse on one of the SMAGs and record the response on the other SMAG. In-house software based on Matlab was used in order to compute the time of arrival of the wave. The results were used to calibrate for the delay in the sensor-actuator line mainly due to the distance between the actual PZT patch and the surface of the

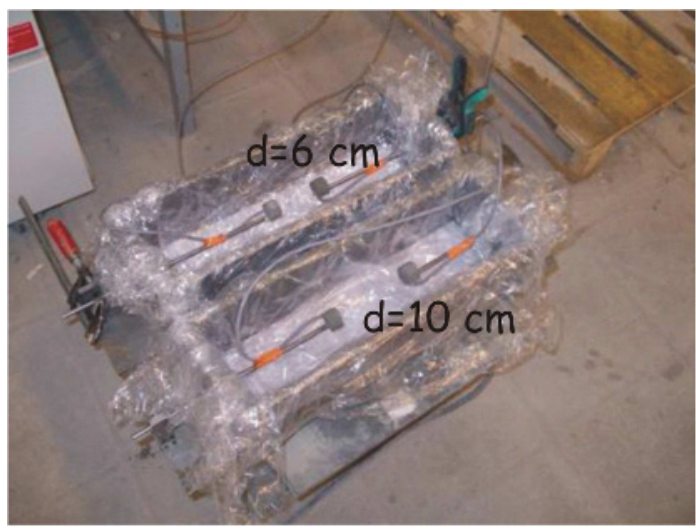

Fig. 3. Prismatic molds with SMAGs before pooring the concrete

SMAGs, as well as delays in the Freshcon hardware. Concrete was then poored and monitoring of the $P$-wave velocity was performed during the first 24 hours under constant temperature $\left(20^{\circ} \mathrm{C}\right)$ and under sealed conditions. With a distance $d=10 \mathrm{~cm}$, the wave was not strong enough to reach the receiver at very early age. With a shorter distance $d=6 \mathrm{~cm}$ which is equivalent to the distance used in the Freshcon mold, we were able to measure the $P$-wave velocity even at very early age. For this reason, the results presented in this paper focus on the mold with $d=6 \mathrm{~cm}$ only.

The results obtained with the SMAGs with a distance of $6 \mathrm{~cm}$ (exact distance is $5.6 \mathrm{~cm}$ ) are compared to the results obtained with the classical Freshcon system with a U-shaped mold for the same concrete on Figure 4 where the evolution of the $P$-wave velocity is plotted as a function of time. The two curves are in very good agreement although there are some discrepancies at very early age.

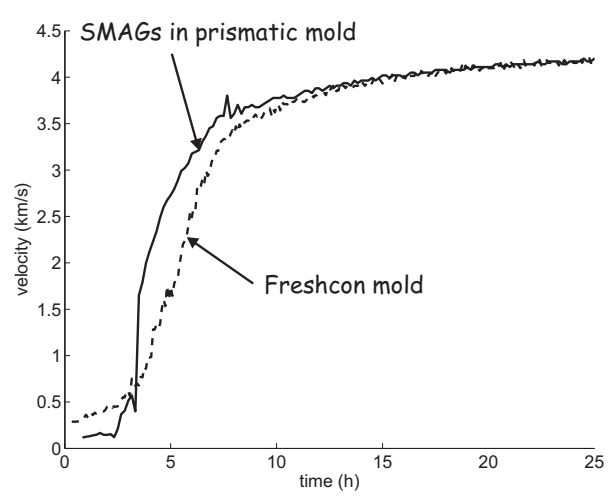

Fig. 4. Comparison of the measured $P$-wave velocity as a function of time using the classical Freshcon system with a U-shaped mold and the SMAGs with a distance $d=6 \mathrm{~cm}$

\section{Conclusion}

Embedded piezoelectric transducers have been proposed for the monitoring of the ultrasonic $P$-wave velocity of concrete from 0 to 24 hours. The transducers are based on the "Smart Aggregate" (SMAG) concept previously developed at the University of Houston, Texas. Two SMAG 
transducers have been designed and produced in our laboratory and embedded in a prismatic mold. The $P$-wave velocity has been monitored during the first 24 hours after concrete casting. The results are in very good agreement with results obtained on the same concrete mixture using a classical method based on a dedicated mold and external transducers (the Freshcon system). Extraction of the wave velocity with a good accuracy at very early age is however difficult and some improvements are possible, using for example optimized and more powerful transducers. This is the subject of a next step of this research. As the results of this study are promising, we intend to use SMAGs in more complex test configurations (i.e. applying mechanical and thermal boundary conditions at early age) for the estimation of the wave velocity and concrete mechanical properties at early age.

\section{Acknowledgements}

We would like to thank Prof. G. Song and Dr. H. Gu from the University of Houston, Texas, for providing the first samples of Smart Aggregates and for the fruitful discussions on this topic, as well as Brice Delsaute, our colleague from ULB-BATir for sharing ideas with us on this topic.

\section{References}

1. H.W. Reinhardt and C.U. Grosse, Continuous Monitoring of setting and hardening of mortar and concrete, Construction and Building Materials 18, (2004) pp.145-154.

2. N. Robeyst, E. Gruyaert, C.U. Grosse and N. De Belie, Monitoring the setting of concrete containing blastfurnace slag by measuring the ultrasonic p-wave velocity, Cement and Concrete Research 38, (2008), pp.11691176.

3. A. Darquennes, S. Staquet and B. Espion, Determination of time-zero and its effect on autogenous deformation evolution, European Journal of Environmental and Civil Engineering 15/7, (2011), pp.1017-1029.

4. H. Gu, G. Song, H. Dhonde, Y.L. Mo and S. Yan, Concrete early-age strength monitoring using embedded piezoelectric transducers, Smart Materials and Structures 15, (2006), pp.1837-1845

5. G. Song, H. Gu and Y.L. Mo, Smart aggregates: multifunctional sensors for concrete structures - a tutorial and a review, Smart Materials and Structures 17, (2008), 17 pages 